\title{
Management of thrombocytopenia in advanced liver disease
}

\author{
VGR Gangireddy MBBS ${ }^{1}$, PC Kanneganti $\mathrm{MBBS}^{2}$, S Sridhar MBBS MPH FRCP FACP1, \\ $\mathrm{S}$ Talla MBBS ${ }^{3}$, T Coleman MD FACP 4
}

VGR Gangireddy, PC Kanneganti, S Sridhar, S Talla, T Coleman. Management of thrombocytopenia in advanced liver disease. Can J Gastroenterol Hepatol 2014;28(10):558-564.

Thrombocytopenia (defined as a platelet count $<150 \times 10^{9} / \mathrm{L}$ ) is a wellknown complication in patients with liver cirrhosis and has been observed in $76 \%$ to $85 \%$ of patients. Significant thrombocytopenia (platelet count $<50 \times 10^{9} / \mathrm{L}$ to $75 \times 10^{9} / \mathrm{L}$ ) occurs in approximately $13 \%$ of patients with cirrhosis. Thrombocytopenia can negatively impact the care of patients with severe liver disease by potentially interfering with diagnostic and therapeutic procedures. Multiple factors can contribute to the development of thrombocytopenia including splenic platelet sequestration, immunological processes, bone marrow suppression by chronic viral infection, and reduced levels or activity of the hematopoietic growth factor thrombopoietin. The present review focuses on the etiologies and management options for severe thrombocytopenia in the setting of advanced liver disease.

Key Words: Advanced liver disease; Cirrhosis; Splenectomy; Splenic artery embolization; Thrombocytopenia; Thrombopoietin stmulators

T hrombocytopenia is a well-known complication in advanced liver disease, with an incidence of $77 \%$ to $85 \%$ in patients with cirrhosis (1). Patients with chronic liver disease and thrombocytopenia are at increased risk for bleeding, requiring recurrent platelet transfusions, increased ambulatory visits and inpatient hospital stays compared with individuals without thrombocytopenia (2). It has been estimated that the annual health care costs of a patient with hepatitis $\mathrm{C}$ virus (HCV) infection with and without thrombocytopenia is $\$ 37,924$ and $\$ 12,174$, respectively (2). Thrombocytopenia can also interfere with diagnostic and therapeutic procedures in patients with advanced liver disease. For example, patients with chronic HCV-related cirrhosis, who are not candidates for liver transplantation, often cannot be treated with interferon (IFN) therapy because of low platelet counts. This is clinically important because successful therapy for $\mathrm{HCV}$ infection may reduce the progression to hepatocellular carcinoma (3). Liver transplantation can be safely avoided if timely IFN therapy is provided to HCV patients. Repetitive platelet transfusions are not a practical solution to thrombocytopenia because of the short half-life of platelets and the associated alloimmunization that ultimately develops. The risk of transfusionassociated complications also significantly increases with repeated transfusions. The characterization of thrombocytopenia in these patient populations in the literature is sparse; accordingly, the present review concentrates on the etiology and management of thrombocytopenia in 'advanced liver disease' as a whole and HCV infection when mentioned.

\section{ETIOLOGY}

Thrombocytopenia in patients with advanced liver disease is secondary to hypersplenism, possible immune-mediated mechanisms, direct viral suppression of platelet production and decreased thrombopoietin (TPO) production from the diseased liver. The general approach to the diagnosis and major mechanisms of thrombocytopenia is highlighted in Figure 1.

\section{La prise en charge de la thrombocytopénie en cas de maladie hépatique avancée}

La thrombocytopénie (définie comme une numération plaquettaire inférieure à $150 \times 10^{9} / \mathrm{L}$ ) est une complication bien connue chez les patients atteints de cirrhose du foie, qui s'observe chez $76 \%$ à $85 \%$ des patients. Une thrombocytopénie importante (numération plaquettaire de moins de à $50 \times 10^{9} / \mathrm{L}$ à $75 \times 10^{9} / \mathrm{L}$ ) se déclare chez environ $13 \%$ des patients atteints de cirrhose. La thrombocytopénie peut nuire aux soins des patients atteints d'une maladie hépatique grave et compromettre les interventions diagnostiques et thérapeutiques. De nombreux facteurs peuvent contribuer à l'apparition d'une thrombocytopénie, y compris la séquestration des plaquettes spléniques, les processus immunologiques, la suppression de la moelle épinière par une infection virale chronique et le ralentissement de la thrombopoïétine, un facteur de croissance hématopoïétique. La présente analyse porte sur les étiologies et les options de prise en charge de la thrombocytopénie grave en cas de maladie hépatique avancée.

\begin{abstract}
Hypersplenism
Most cases of thrombocytopenia in the setting of liver disease are associated with splenomegaly (4). Splenomegaly is defined as enlargement of the spleen, diagnosed either on physical examination or imaging studies. In general, splenic enlargement to approximately $285 \mathrm{~g}$ is palpable (5). Normal splenic size on ultrasound is $<13 \mathrm{~cm}$ in length and $\leq 15 \mathrm{~cm}$ in thickness and, on computed tomography scan is $<10 \mathrm{~cm}$ (6). Hepatic diseases account for 36\% of cases of splenomegaly; $35 \%$ are attributed to hematological conditions, $16 \%$ to infectious diseases (50\% in AIDS/HIV), $4 \%$ to primary spleen disorders, $5 \%$ to inflammatory conditions and $4 \%$ to other causes (7). Splenomegaly is a common finding in patients with cirrhosis and portal hypertension. Conversely, not all patients with cirrhosis and portal hypertension have splenomegaly (8). To date, the reasons behind this discordance are unclear. It has also been noted that portal venous pressure only increases to a certain level, after which portal venous pressure decreases with an increase in total portal systemic shunt and splenic shunt (9). This may partially explain the occasional lack of correlation between portal venous pressure and splenic size. The etiology of splenomegaly in patients with liver cirrhosis is multifactorial and may be a congestive or hyperplastic phenomenon (10). In most cases, increases in portal venous pressure cause splenic congestion, thereby leading to the development of splenomegaly with resulting increased platelet sequestration and subsequent thrombocytopenia.
\end{abstract}

\section{Immunological mechanisms of thrombocytopenia in cirrhosis and HCV patients}

Noting a variable response in thrombocytopenia after portal vein decompression in cirrhotic patients, Jabbour et al (11) questioned whether other mechanisms of thrombocytopenia may be occurring in specific patient populations. It has been long observed that HCV

\footnotetext{
${ }^{1}$ Georgia Regents University, Augusta, Georgia; ${ }^{2}$ Helena Regional Medical Center, Helena, Arkansas, USA; ${ }^{3}$ Luzhou Medical College, Luzhou, China;

${ }^{4}$ Archbold Medical Center, Thomasville, Georgia, USA

Correspondence: Dr VGR Gangireddy, Georgia Regents University, 1120 15th Street, Augusta, Georgia 30912, USA. Telephone 706-721-2238,

fax 706-721-0331,e-mail venureddy82@gmail.com
}

Received for publication April 2, 2014. Accepted August 10, 2014 
patients are prone to several autoimmune disorders, suggesting the possibility of an autoimmune etiology for thrombocytopenia in this patient population (12-14). A recent study by Olariu et al (15) investigating thrombocytopenia in HCV patients found that both decreased platelet production by bone marrow suppression (the 'central' mechanism) and increased destruction by autoimmune processes (the 'peripheral' mechanism) was present in approximately $93.3 \%$ of patients with severe thrombocytopenia and $64 \%$ of patients with moderate thrombocytopenia. However, these conclusions should be viewed with caution because there were several limitations to the study, such as excluding patients with cirrhosis and, thereby, potentially excluding the majority of patients with splenomegaly. Moreover, there was no mention of the bone marrow biopsy or megakaryocyte quantification methods used. It was also noted that only dual-colour immunofloresence and flow cytometry could identify both mature and immature megakaryocytes as opposed to light microscopy, which may exclude immature megakaryocytes (16).

The role of the spleen in the autoimmune process of immune thrombocytopenic purpura (ITP) has been extensively studied (17). The etiology of thrombocytopenia in liver cirrhosis may have some similarities with ITP. Autoimmune antibodies possibly contribute to the immunological destruction of platelets in both; however, the severity of thrombocytopenia in liver cirrhosis is typically less than that found in ITP. This may be explained by impaired functioning of the reticuloendothelial system, thereby decreasing platelet opsonizing capacity acting via $F_{c}$ receptors in cirrhotic patients (18). Other explanations may be differences in the subclass activation of immunoglobulin (Ig) G isotypes in cirrhotic patients. Both platelet-associated antibodies (PAIgG and anti-GP antibodies) and serum circulating antiplatelet antibodies are found in patients with cirrhosis $(19,20)$. Increased PAIgG autoimmune antibodies in cirrhosis patients were first noted by Landolfi et al (21). Subsequent studies have also shown an inverse correlation between platelet counts and PAIgG levels (2224). PAIgG is also increased in many nonimmune causes of thrombocytopenia and hypergammaglobulinemia. The PAIgG assay is not regarded to be an appropriate test for the diagnosis of ITP by the American Society of Hematology; hence, its diagnostic role in HCV or cirrhotic patients is also questionable (25).

The role of other antiplatelet antibodies (anti-GP antibodies) in cirrhosis patients was first studied by Pereira et al (26) in 1995. AntiGPIIb-IIIa antibody-producing B cells are present in approximately $99 \%$ of patients with liver cirrhosis irrespective of the etiology of cirrhosis $(19,26)$. They are found to be the strongest independent factor associated with thrombocytopenia and inversely correlated with platelet count (19). The glycocalicin index, which measures platelet turnover rate, is abnormally high in liver cirrhosis patients. Reticulated platelets, which reflect the rate of bone marrow platelet production, is increased in all patients with alcoholic cirrhosis, hepatitis B virus cirrhosis and ITP patients $(20,27-29)$. This, in addition to the presence of anti-GPIIb-IIIa autoantibodies, suggests at least some immunological component of platelet destruction and thrombocytopenia in some advanced liver disease patients (20). The low reticulated platelet count in the HCV subgroups may be explained by the central effect of $\mathrm{HCV}$ in bone marrow suppression (20).

\section{The role of TPO}

Immunological processes may partially explain thrombocytopenia in cirrhotic patients in whom portal vein congestion has not been demonstrated; however, in some cases, immune complexes cannot be implicated. There is mounting evidence that impaired hepatic production of TPO may be a major cause of thrombocytopenia in liver disease. TPO is synthesized in the liver and is the principle physiological regulator of platelet production (30). Thrombocytopenic patients with advanced liver disease have inappropriately low levels of TPO (3133). Patients with splenomegaly and normal platelet counts have significantly higher TPO levels than those with thrombocytopenia, which suggests that higher TPO levels result in a compensatory

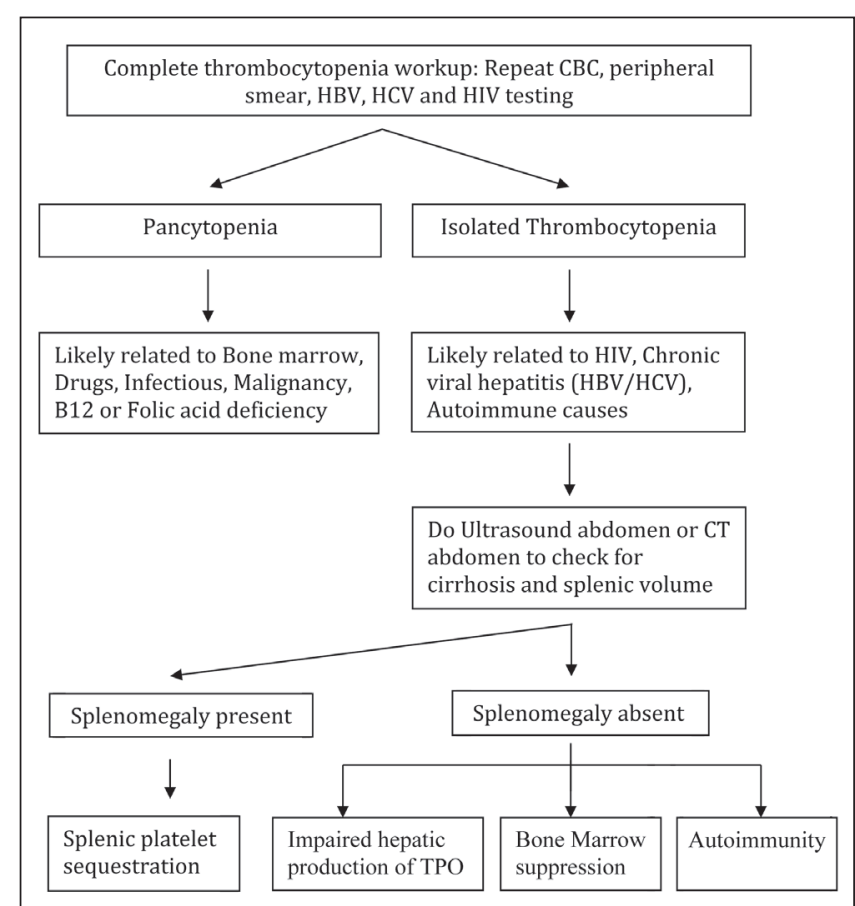

Figure 1) General approach and mechanism to the diagnosis of thrombocytopenia in liver disease. CBC Complete blood count; CT Computed tomography; HBV Hepatitis B virus; HCV Hepatitis C virus; TPO Thrombopoietin

increase in platelet production (34). Serum TPO levels correlate inversely with the severity of liver disease as reflected by the degree of fibrosis, Child-Pugh class and other synthetic measures of liver function $(35,36)$. TPO levels and platelet counts increase after orthotopic liver transplantation, strongly supporting impaired TPO production as a primary cause of thrombocytopenia in at least some patients $(37,38)$.

\section{MANAGEMENT: OVERVIEW}

The management of thrombocytopenia in cirrhotic patients has been a challenging problem for many years. Splenorenal shunts were developed in the 1960s but later abandoned due to a high mortality rate from liver failure $(39,40)$. Splenectomy and, later, partial splenectomy (PS), gained popularity because of fewer complications associated with the procedure. With refined laparoscopic techniques, splenectomies have been performed since the late 1990s with minimal complications and better resolution of thrombocytopenia compared with PS. Splenic embolization has been successfully performed since the 1970s. Now, partial splenic embolization (PSE) is gaining in popularity. Newer techniques, such as radiofrequency ablation (RFA) and TPO stimulators, are currently being investigated to treat the thrombocytopenia associated with liver disease. Here, we discuss the merits and drawbacks of each intervention, with a special emphasis on recent advances in the management of thrombocytopenia in chronic liver disease patients (Table 1). Figures 2 and 3 summarize the general approach to management.

\section{Splenectomy}

Splenomegaly is a common complication in patients with cirrhosis, with portal hypertension being the primary mechanism of pathogenesis. Splenectomy is a common surgical strategy for correcting thrombocytopenia due to hypersplenism. Open splenectomy and laparoscopic splenectomy are the two most widely available procedures commonly performed for severe thrombocytopenia.

Since the 1950s, open splenectomies were primarily performed in cirrhotic patients with splenomegaly to relieve portal hypertension and reduce variceal bleeding $(41,42)$. Due to the high risk for bleeding, 
TABLE 1

Summary of management of thrombocytopenia in liver disease

\begin{tabular}{|c|c|c|c|}
\hline Procedure & Advantages & Disadvantages & Comments \\
\hline Laparoscopic splenectomy & $\begin{array}{l}\text { - Most effective in improving } \\
\text { thrombocytopenia } \\
\text { - Can be performed in patients with low } \\
\text { splenic volumes (<400 mL) } \\
\text { - Lower complication rates compared with } \\
\text { open splenectomy. }\end{array}$ & $\begin{array}{l}\text { - Overall complication rates ranges } \\
\text { from } 2.5 \% \text { to } 17 \% \\
\text { - Increased risk for intra- and } \\
\text { postoperative bleeding } \\
\text { - Increased risk for portal vein } \\
\text { thrombosis and splenic vein } \\
\text { thrombosis ( } 19 \% \text { to } 55 \%)\end{array}$ & - Extensively studied \\
\hline Radiofrequency splenic ablation & $\begin{array}{l}\text { - Lower complication rates, better cost } \\
\text { effectiveness and convenience compared } \\
\text { with PSE } \\
\text { - }>70 \% \text { RFA showed sustained platelet } \\
\text { counts similar to splenectomized patients } \\
\text { - Additional improvement in liver function }\end{array}$ & $\begin{array}{l}\text { - Suboptimal ablation can result in } \\
\text { unsustained platelet counts }\end{array}$ & $\begin{array}{l}\text { - Newer technique } \\
\text { - Further randomized control studies and } \\
\text { clinical trials are needed to evaluate its } \\
\text { effectiveness }\end{array}$ \\
\hline Antiviral therapy & - No procedure-related complications & $\begin{array}{l}\text { - Unsustained improvement in } \\
\text { thrombocytopenia } \\
\text { - Only shown to improve mild } \\
\text { thrombocytopenia }\end{array}$ & $\begin{array}{l}\text { - Only case reports and case series } \\
\text { - Further randomized control studies and } \\
\text { clinical trials are needed to evaluate its } \\
\text { effectiveness }\end{array}$ \\
\hline Immune suppression & - No procedure-related complications & $\begin{array}{l}\text { - Not used for thrombocytopenia } \\
\text { related to liver diseases or HCV } \\
\text { - Shown to increase chances of } \\
\text { recurrence and viral load in post } \\
\text { transplant HCV patients }\end{array}$ & $\begin{array}{l}\text { - Used in patients with ITP } \\
\text { - Not be recommended to improve } \\
\text { thrombocytopenia associated with liver } \\
\text { disease }\end{array}$ \\
\hline Thrombopoietin stimulators & $\begin{array}{l}\text { - No procedure-related complications } \\
\text { - Can be considered in patients who are } \\
\text { poor surgical candidates }\end{array}$ & - Portal vein thrombosis & $\begin{array}{l}\text { Eltrombopag is approved for treatment } \\
\text { of thrombocytopenia in chronic HCV } \\
\text { patients who are considered for HCV } \\
\text { therapy }\end{array}$ \\
\hline
\end{tabular}

AASLD American Association for the Study of Liver Diseases; HCV Hepatitis C virus; ITP Immune thrombocytopenic purpura; PSE Partial splenic embolization; RFA Radiofrequency ablation; TIPS Transjugular intrahepatic portosystemic shunts

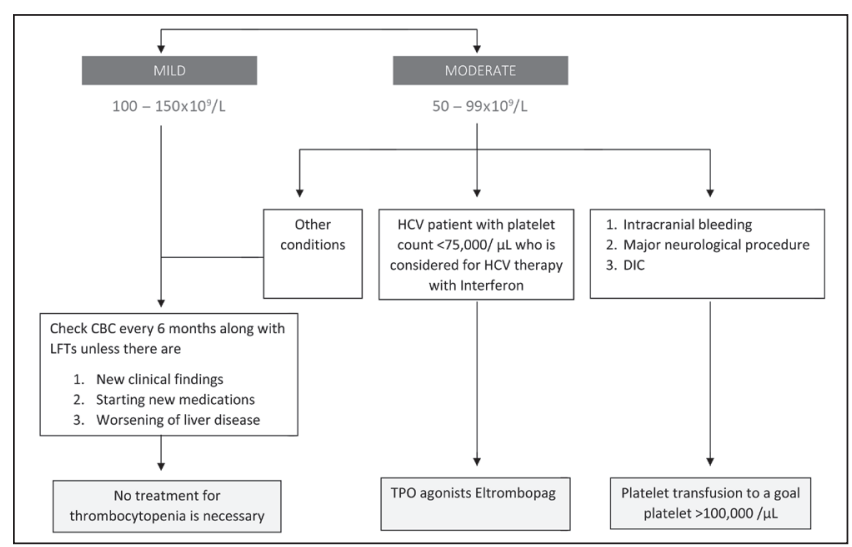

Figure 2) Cirrhosis and thrombocytopenia. CBC Complete blood count; HCV Hepatitis C virus; DIC Disseminated intravascular coagulation; LFTs Liver function tests; TPO Thrombopoietin

some studies preferred shunt procedures to open splenectomy $(43,44)$. Additional complications reported after open splenectomy include portal vein thrombosis ( $8 \%$ to $10 \%)$ and wound pain $(45,46)$. Due to advances in laparoscopic surgical techniques, laparoscopic splenectomies have been performed since the early 1990s on patients who were initially not considered for this procedure $(47,48)$. Comparative studies investigating open versus laproscopic splenectomy in cirrhosis patients to improve platelet counts were largely missing in the literature until recently, when Hayashi et al (49) first published a case

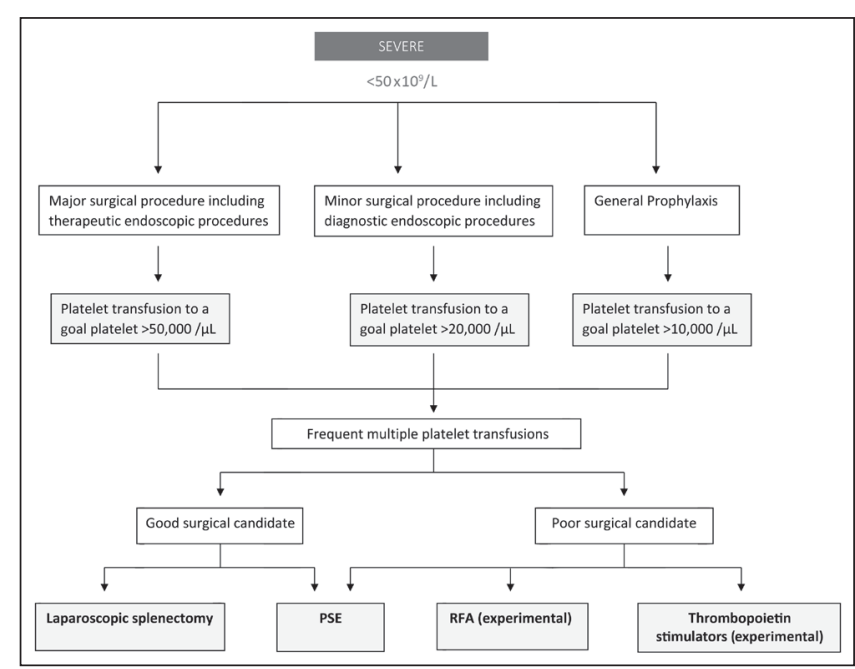

Figure 3) Cirrhosis and thrombocytopenia. PSE Partial splenic embolization; RFA Radiofrequency ablation

series involving HCV patients. In this study, the mean hospital stay, significant complication rate and transfusion rate were nine days, $14 \%$ and $71 \%$ for open splenectomy compared with 2.6 days, $0 \%$ and $0 \%$, respectively, for laparoscopic splenectomy. Other recent studies have favoured laparoscopic approaches to decrease complication rates. Compared with open splenectomy, laparoscopic splenectomy has resulted in less blood loss and shorter hospital stays (50). Currently, 
TABLE 2

Management of thrombocytopenia due to cirrhosis at a single centre

\begin{tabular}{lll}
\hline Preoperative splenic volume & Procedure & Target \\
\hline$<400 \mathrm{~mL}$ & Left splenectomy & \\
$400 \mathrm{~mL}$ to $700 \mathrm{~mL}$ & $\begin{array}{c}\text { Single partial splenic embolization or laparoscopic splenectomy } \\
\text { (in selective cases) }\end{array}$ & Infarcted splenic area (Infarcted splenic volume $<540 \mathrm{~mL})$ \\
$>700 \mathrm{~mL}$ & $\begin{array}{l}\text { Repeated partial splenic embolization (two-month interval) or } \\
\text { laparoscopic splenectomy (in selective cases) }\end{array}$ & $\begin{array}{c}\text { Noninfarcted splenic area (Noninfarcted splenic ratio }<20 \% \\
\text { and noninfarcted splenic volume }<170 \mathrm{~mL})\end{array}$ \\
\hline
\end{tabular}

Data adapted from reference 64

due to lack of strong supportive evidence of efficacy and a high associated complication rate, open splenectomy to improve thrombocytopenia is not commonly practiced or recommended.

Portal and splenic vein thrombosis are the main complications of laparoscopic splenectomy (19\% to 55\%) compared with open splenectomy $(8 \%$ to $10 \%)(45,46,51-54)$. Risk factors for thrombosis include larger spleen size and large splenic vein diameter (55). The most significant complication following laparoscopic splenectomy is bleeding. The amount of bleeding in laparoscopic splenectomy groups is significantly less compared with open splenectomy groups $(51,56-58)$. The conversion rate from laparoscopic to open splenectomy due to bleeding ranges from $0 \%$ to $9.6 \%(56,58)$. Overall complication rates in cirrhotic patients range from $2.5 \%$ to $17 \%(57,59)$. However, in patients with massive splenomegaly, the complication rate can be as high as $56 \%$ (60). The indication of laparoscopic splenectomy in the management of thrombocytopenia is largely limited because of the associated surgical complications with the procedure, as mentioned above.

\section{Splenic artery embolization}

The use of splenic artery embolization (SAE) in the management of thrombocytopenia was first reported by Maddison (61) in 1973 as a proposed alternative to splenectomy in surgically unfit patients. The two types of SAE techniques widely published in the literature include total embolization and partial embolization. Due to an increased risk for splenic abscess from total splenic embolization, partial SAE (PSE) is now the preferred option in patients who are candidates $(62,63)$. Embolization occludes the arterial supply of the spleen peripherally with ischemic necrosis of functional splenic tissue followed by a decrease in spleen size. Partial embolization allows the preservation of some normal splenic tissue and thereby avoids the theoretical risk of overwhelming postembolization sepsis. The role of preoperative splenic volume in the management of thrombocytopenia in patients with cirrhosis is a matter of significant debate. Unfortunately, there were no clear guidelines to direct splenectomy or PSE based on splenic volume. The recommended splenic infarct volume to effectively increase the platelet counts (at one year) and decrease the post-PSE complication is between $388 \mathrm{~mL}$ and $540 \mathrm{~mL}$ (64). One institution's approach is shown in Table 2; however, this approach needs to be further validated (65). In patients with cirrhosis and splenic volume $<400 \mathrm{~mL}$, splenectomy is mainly preferred because PSE can cause significant inflammatory reactions and preclude further splenectomy if needed. In patients with splenic volume $<700 \mathrm{~mL}$, the infarcted splenic volume is shown to correlate $(\mathrm{r}=0.53 ; \mathrm{P} \leq 0.001)$ with the longterm (one year) increase in platelet counts; however, in patients with splenic volume $\geq 700 \mathrm{~mL}$, noninfarcted splenic volume $(\mathrm{r}=-0.71$; $\mathrm{P}=0.003)$ and splenic infarction ratio $(\mathrm{r}=0.72 ; \mathrm{P}=0.002)$ were shown to correlate (65).

The extent and sustainability of improvements in platelet counts appears to be dependent on the extent of SAE. It has been reported that embolization of $<30 \%$ of splenic mass results in an unsustained improvement in platelet counts, but embolization of $>50 \%$ is associated with an increased risk for complications $(66,67)$. Complication rates are reported to be approximately $28 \%$ with $<50 \%$ embolization, $56 \%$ with $50 \%$ to $70 \%$ embolization, and $95 \%$ with $>70 \%$ embolization (68). The complications reported with PSE are pneumonia, peritonitis, splenic abscess and portal vein thrombosis (67). Laparoscopic splenectomy has a higher morbidity rate compared with PSE ( $16 \%$ to $36 \%$ versus $0 \%$ to $16 \%$, respectively) $(69,70)$. Splenic abscess is a severe complication of PSE, with a reported incidence of up to $16 \%$; death may occur in $6 \%$ of cases $(69,70)$. Retrospective series suggest that PSE can control cytopenias in nearly all patients $(70,71)$. In a randomized trial, PSE was comparable with splenectomy with regard to increasing platelet counts $\left(211 \times 10^{9} / \mathrm{L}\right.$ versus $240 \times 10^{9} / \mathrm{L}$ at two weeks, and $146 \times 10^{9} / \mathrm{L}$ versus $322 \times 10^{9} / \mathrm{L}$ at six months). The patients in the PSE group also experienced fewer episodes of portal vein thrombosis (72).

It should be noted that in other studies, patients with HCV infection had a poorer response rate to PSE, which was believed to be secondary to possible immunological mechanisms contributing to the thrombocytopenia, which PSE could not correct $(73,74)$.

\section{RFA of the spleen}

RFA of the spleen is a minimally invasive, relatively new procedure that has shown promising results in patients with cirrhosis and splenomegaly (75). In a randomized controlled trial comparing RFA with laparoscopic splenectomy, platelet counts improved after RFA but were not sustained after 12 months and 24 months of follow-up (76). Suboptimal ablation was likely the reason for the unsustained platelet counts. Patients with $>70 \%$ ablation showed sustained platelet counts similar to splenectomized patients. The other benefits of RFA were improved liver function secondary to improved hepatic artery blood flow to the liver, increased oxygenation and decreased liver sinusoidal congestion (77). The main advantages of RFA over PSE were lower complication rates, cost effectiveness and convenience. The major complications in this group of patients included hemorrhagic shock and intra-abdominal bleeding. Complications such as hyperpyrexia, splenic rupture or abscess, which are commonly observed in patients with PS, were absent in patients treated with RFA (76). Further clinical trials with longer follow-up studies are needed to definitively elucidate its effectiveness.

\section{Shunt procedures}

Splenic congestion is believed to be the primary mechanism of thrombocytopenia in patients with cirrhosis. After the success of surgical splenectomy in improving thrombocytopenia, the focus shifted to shunt procedures. Shunt procedures decompress the spleen and decrease portal pressures, thereby creating a 'physiological splenectomy'. The types of shunts widely published in the literature for these purposes are portocaval shunts, splenorenal shunts and transjugular intrahepatic portosystemic shunts (TIPS). When compared with a control group, patients with portocaval shunts and distal splenorenal shunts have experienced more complications, such as hepatic encephalopathy and hepatic failure, and minimal improvements in hypersplenism and thrombocytopenia $(78,79)$. These approaches have now been largely abandoned. TIPS has been in use for $>20$ years to treat the complications of portal hypertension. Several case series suggested an improvement in the platelet count within a few days of TIPS placement (80-82). However, prospective series do not support this because the mean platelet counts appear to remain unchanged after TIPS $(83,84)$. Complications include encephalopathy (up to $45 \%$ ) and 
portal vein thrombosis (15\%) (85). Recent practice guidelines update the use of TIPS in cirrhosis. TIPS for the treatment of hypersplenism are currently discouraged by the American Association for the Study of Liver Diseases (85).

\section{Antiviral therapy to improve thrombocytopenia}

The role of antiviral therapy in the management of thrombocytopenia is a much-debated topic. Direct viral suppression of megakaryocytes and, therefore, TPO deficiency causing thrombocytopenia, has been proposed. New questions have arisen as to whether the eradication of HCV would itself improve thrombocytopenia.

In one of the earlier case series investigasting the treatment of $\mathrm{HCV}$ to improve thrombocytopenia with or without cirrhosis, Rajan and Liebman (86) showed that IFN therapy can improve platelet counts in severely thrombocytopenic patients (range $16 \times 10^{9} / \mathrm{L}$ to $48 \times 10^{9} / \mathrm{L}$ ) (86). In a study involving eight patients, $63 \%$ (five of eight) of patients experienced improvement in their platelet counts to $>50 \times 10^{9} / \mathrm{L}$. Two patients had neither an improvement in platelet count nor an antiviral response to IFN. The most significant response (one of one) was observed in a patient who achieved a sustained virological response (SVR). In patients with cirrhosis (three of eight), platelet counts improved in two. Patients who had improved platelet counts also had decreased rheumatoid factor antibodies and cryoglobulins, as well as improved transaminase levels. In another study (74), the authors showed that all of the patients $(n=5)$ with thrombocytopenia $\left(<150 \times 10^{9} / \mathrm{L}\right)$ who achieved an SVR with IFN improved their platelet counts at least by $5 \%$ (two patients between $5 \%$ and $15 \%$, one between $15 \%$ and $25 \%$, and two $>25 \%$ ). The limitations of this study were small sample size, the majority of the patients treated with IFN in the thrombocytopenia group were mildly thrombocytopenic ( $80 \%$ of the patient's platelets counts $\left.>100 \times 10^{9} / \mathrm{L}\right)(74)$. Further randomized control studies and clinical trials are needed to evaluate the role of antiviral therapy in the management of thrombocytopenia.

\section{Immune suppression for the treatment of thrombocytopenia}

The role of autoantibodies in thrombocytopenia, especially in HCV, is well known. Steroids and other immunosuppressive agents have been used for the treatment of ITP. The treatment of HCV in patients with liver transplantation shows that immunosuppression increases the viral load and recurrence of HCV infection even after achieving an SVR (87-90). Presently, immunosuppression cannot be recommended to improve thrombocytopenia in this patient population.

\section{TPO stimulators}

Clinical studies investigating thrombopoietic growth factors showed that they were effective in increasing the platelet count in several clinical settings including myelodysplastic syndromes, nonmyeloablative chemotherapy and ITP. The development of first-generation thrombopoietic growth factors (recombinant human TPO and pegylated recombinant human megakaryocyte growth and development factor [PEG-rHuMGDF]) was stopped due to development of antibodies to PEG-rHuMGDF (91). Of the second-generation thrombopoietic growth factors, only romiplostim and eltrombopag have been extensively tested in human diseases. Both increased platelet counts in patients with ITP and could do so for a prolonged time without apparent untoward effects. Both drugs are now United States Food $\&$ Drug Administration-approved for the treatment of patients with chronic ITP. Studies are ongoing in patients with thrombocytopenia related to chemotherapy, hepatitis $\mathrm{C}$ and myelodysplastic syndromes. McHutchinson et al (92) conducted a phase II randomized controlled trial involving 74 patients with HCV-related cirrhosis. Only 6\% of patients in the placebo group completed the 12-week antiviral course. In contrast, $36 \%, 53 \%$ and $65 \%$ of patients receiving $30 \mathrm{mg}, 50 \mathrm{mg}$ and $75 \mathrm{mg}$ of eltrombopag completed the same antiviral course, respectively. Moreover, $75 \%$ to $95 \%$ of patients in the eltrombopag group achieved the primary end point (platelet count $100 \times 10^{9} / \mathrm{L}$ at week 4 ) in a dosedependent manner (92). The Eltrombopag Evaluated for Its Ability to Overcome Thrombocytopenia and Enable Procedures (ELEVATE) study is a randomized, double-blind, placebo-controlled, multinational follow-up study in patients with thrombocytopenia and chronic liver disease (93). It was terminated following the identification of an imbalance of thrombosis of the portal venous system in the patients treated with eltrombopag versus matching placebo. Six patients $(4 \%)$ in the eltrombopag group and one (1\%) in the placebo group experienced a thrombotic event of the portal venous system. Of note, five of the six patients treated with eltrombopag experienced the portal venous thrombosis at platelet counts $>200 \times 10^{9} / \mathrm{L}$ (93). Eltrombopag was recently United States Food \& Drug Administration-approved for thrombocytopenia in patients with $\mathrm{HCV}$ who are eligable for antiviral therapy with IFN and ribavirin (94). Its effects on newer antiviral medications, such as sofosbuvir and semepivir, is yet to be determined. Phase III studies of romiplostim treatment in $\mathrm{HCV}$-associated thrombocytopenia are currently ongoing. Some of the risk for thrombosis in these patients is dose related, although portal vein thrombosis has also been reported with this agent (95). TPO stimulators may play an important role in the management of thrombocytopenia in patients with advanced liver disease, primarily in patients who are poor surgical candidates.

\section{CONCLUSIONS}

Hypersplenism in patients with advanced liver disease remains a challenging issue and thrombocytopenia is a multifactorial problem. Currently available therapeutic solutions are not without significant complications. Intuitively, it would appear that correcting the underlying liver disease with immune therapy, use of immunosuppressives or liver transplantation would provide the best solution with fewest complications. Less is known about the impact of platelet autoantibodies and direct viral suppression of megakaryocytes. Management of thrombocytopenia in patients with cirrhosis should be a goal-oriented and team approach. In HCV patients with high viral loads and mild thrombocytopenia without accompanying cirrhosis, IFN therapy can be safely considered in the hope of improving platelet counts. Combination therapy consisting of pegylated IFN and TPO stimulators, such as eltrombopag, can also be considered in these patients. In patients with splenomegaly, PSE and laparoscopic splenectomy can be considered as therapeutic options. The role of immune suppression and TPO stimulators in patients with massive splenomegaly in whom these interventions are considered unsafe is an area for ongoing investigation.

DISCLOSURES: The authors have no financial disclosures or conflicts of interest to declare.

\section{REFERENCES}

1. Qamar AA, Grace ND, Groszmann RJ, et al; Portal Hypertension Collaborative Group. Incidence, prevalence, and clinical significance of abnormal hematologic indices in compensated cirrhosis. Clin Gastroenterol Hepatol 2009; 7:689-95.

2. Poordad F, Theodore D, Sullivan J, Grotzinger K. Medical resource utilisation and healthcare costs in patients with chronic hepatitis $\mathrm{C}$ viral infection and thrombocytopenia. J Med Econ 2011;14:194-206.

3. Morihara D, Kobayashi M, Ikeda K, et al. Effectiveness of combination therapy of splenectomy and long-term interferon in patients with hepatitis $C$ virus-related cirrhosis and thrombocytopenia. Hepatol Res 2009;39:439-47.

4. Sakai K, Iwao T, Oho K, Toyonaga A, Sata M. Propranolol ameliorates thrombocytopenia in patients with cirrhosis. J Gastroenterol 2002;37:112-8.

5. Aito $H$. The estimation of the size of the spleen by radiological methods. A comparative radiographic, gamma imaging and ultrasonic study. Ann Clin Res 1974; (6 Suppl):1-54.

6. Tamayo SG, Rickman LS, Mathews WC, et al. Examiner dependence on physical diagnostic tests for the detection of splenomegaly: A prospective study with multiple observers. J Gen Intern Med 1993;8:69-75. 
7. O'Reilly RA. Splenomegaly in 2,505 patients at a large university medical center from 1913 to 1995. 1963 to 1995: 449 patients. West J Med 1998;169:88-97.

8. Gibson PR, Gibson RN, Ditchfield MR, Donlan JD. Splenomegaly - an insensitive sign of portal hypertension. Aust N Z J Med 1990;20:771-4.

9. Ohnishi K, Nakayama T, Saito M, et al. Effects of propranolol on portal hemodynamics in patients with chronic liver disease. Am J Gastroenterol 1985;80:132-5.

10. Bolognesi M, Merkel C, Sacerdoti D, Nava V, Gatta A. Role of spleen enlargement in cirrhosis with portal hypertension. Dig Liver Dis 2002;34:144-50.

11. Jabbour N, Zajko A, Orons P, Irish W, Fung JJ, Selby RR. Does transjugular intrahepatic portosystemic shunt (TIPS) resolve thrombocytopenia associated with cirrhosis? Dig Dis Sci 1998;43:2459-62.

12. Clifford BD, Donahue D, Smith L, et al. High prevalence of serological markers of autoimmunity in patients with chronic hepatitis C. Hepatology 1995;2:613-9.

13. Hadziyannis SJ. Nonhepatic manifestations and combined diseases in HCV infection. Dig Dis Sci 1996;41(12 Suppl):63S-74S.

14. Tran A, Benzaken S, Yang G, et al. Chronic hepatitis C and autoimmunity: Good response to immunosuppressive treatment. Dig Dis Sci 1997;42:778-80.

15. Olariu M, Olariu C, Olteanu D. Thrombocytopenia in chronic hepatitis C. J Gastrointest Liver Dis 2010;19:381-5.

16. Law HK, Bol SJ, Palatsides M, Williams NT. Analysis of human megakaryocytic cells using dual-color immunofluorescence labeling. Cytometry 2000;41:308-15.

17. Kuwana M, Okazaki Y, Kaburaki J, Kawakami Y, Ikeda Y. Spleen is a primary site for activation of platelet-reactive $T$ and $B$ cells in patients with immune thrombocytopenic purpura. J Immunol 2002;168:3675-82.

18. Rimola A, Soto R, Bory F, Arroyo V, Piera C, Rodes J. Reticuloendothelial system phagocytic activity in cirrhosis and its relation to bacterial infections and prognosis. Hepatology 1984;4:53-8.

19. Kajihara M, Kato S, Okazaki Y, et al. A role of autoantibodymediated platelet destruction in thrombocytopenia in patients with cirrhosis. Hepatology 2003;37:1267-76.

20. Pradella P, Bonetto S, Turchetto S, et al. Platelet production and destruction in liver cirrhosis. J Hepatol 2011;54:894-900.

21. Landolfi R, Leone G, Fedeli G, Storti S, Laghi F, Bizzi B. Platelet-associated IgG in acute and chronic hepatic diseases. Scand J Haematol 1980;25:417-22.

22. Barrison IG, Knight ID, Viola L, Boots MA, Murray-Lion IM, Mitchell TR. Platelet associated immunoglobulins on chronic liver disease. Br J Haematol 1981;48:347-50.

23. Graber D, Giuliani D, Leevy CM, Morse BS. Platelet-associated IgG in hepatitis and cirrhosis. J Clin Immunol 1984;4:108-11.

24. de Noronha R, Taylor BA, Wild G, Triger DR, Greaves M. Inter-relationships between platelet count, platelet IgG, serum IgG, immune complexes and severity of liver disease. Clin Lab Haemato 1991;13:127-35.

25. George JN, Woolf SH, Raskob GE, et al. Idiopathic thrombocytopenic purpura: A practice guideline developed by explicit methods for the American Society of Hematology. Blood 1996;88:3-40.

26. Pereira J, Accatino L, Alfaro J, Brahm J, Hidalgo P, Mezzano D. Platelet autoantibodies in patients with chronic liver disease. Am J Hematol 1995;50:173-8.

27. Michur H, Maślanka K, Szczepiński A, Mariańska B. Reticulated platelets as a marker of platelet recovery after allogeneic stem cell transplantation. Int J Lab Hematol 2008;30:519-25.

28. Thomas-Kaskel AK, Mattern D, Köhler G, Finke J, Behringer D. Reticulated platelet counts correlate with treatment response in patients with idiopathic thrombocytopenic purpura and help identify the complex causes of thrombocytopenia in patients after allogeneic hematopoietic stem cell transplantation. Cytometry B Clin Cytom 2007;72:241-8.

29. Harrison P, Robinson MS, Mackie IJ, Machin SJ. Reticulated platelets. Platelets 1997;8:379-83.

30. Kuter DJ, Begley CG. Recombinant human thrombopoietin: Basic biology and evaluation of clinical studies. Blood 2002;100:3457-69.

31. Martin III TG, Somberg KA, Meng YG, et al. Thrombopoietin levels in patients with cirrhosis before and after orthotopic liver transplantation. Ann Intern Med 1997;127:285-8.
32. Ishikawa T, Ichida T, Matsuda Y, et al. Reduced expression of thrombopoietin is involved in thrombocytopenia in human and rat liver cirrhosis. J Gastroenterol Hepatol 1998;13:907-13.

33. Peck-Radosavljevic M, Zacherl J, Meng YG, et al. Is inadequate thrombopoietin production a major cause of thrombocytopenia in cirrhosis of the liver? J Hepatol 1997;27:127-31.

34. Giannini E, Botta F, Borro P, et al. Relationship between thrombopoietin serum levels and liver function in patients with chronic liver disease related to hepatitis $\mathrm{C}$ virus infection. Am J Gastroenterol 2003;98:2516-20.

35. Kawasaki T, Takeshita A, Souda K, et al. Serum thrombopoietin levels in patients with chronic hepatitis and liver cirrhosis. Am J Gastroenterol 1999;94:1918-22.

36. Giannini E, Borro P, Botta F, et al. Serum thrombopoietin levels are linked to liver function in untreated patients with hepatitis $C$ virusrelated chronic hepatitis. J Hepatol 2002;37:572-7.

37. Peck-Radosavljevic M, Wichlas M, Zacherl J, et al. Thrombopoietin induces rapid resolution of thrombocytopenia after orthotopic liver transplantation through increased platelet production. Blood 2000;95:795-801.

38. Yanaga K, Tzakis AG, Shimada M, et al. Reversal of hypersplenism following orthotopic liver transplantation. Ann Surg 1989;210:180-3.

39. Mutchnick MG, Lerner E, Conn HO. Portal-systemic encephalopathy and portacaval anastomosis: A prospective, controlled investigation. Gastroenterology 1974;66:1005-19.

40. Vang J, Simert G, Hansson JA, Thylen U, Bengmark TS. Results of a modified distal spleno-renal shunt for portal hypertension. Ann Surg 1977;185:224-8.

41. Lord JW Jr. The surgical management of secondary hypersplenism. Surgery 1951;29:407-18.

42. Linton RR, Ellis DS, Geary JE. Critical comparative analysis of early and late results of splenorenal and direct portacaval shunts performed in 169 patients with portal cirrhosis. Ann Surg 1961;154:446-59.

43. Yamamoto S, Hidemura R. Surgical treatment of portal hypertension with special reference to the feature of intrahepatic circulatory disturbances. Jpn Circ J 1964;28:178-80.

44. El-Khishen MA, Henderson JM, Millikan WJ Jr, Kutner MH, Warren WD. Splenectomy is contraindicated for thrombocytopenia secondary to portal hypertension. Surg Gynecol Obstet 1985;160:233-8.

45. Hassn AM, Al-Fallouji MA, Ouf TI, Saad R. Portal vein thrombosis following splenectomy. Br J Surg 2000;87:362-73.

46. Winslow ER, Brunt LM, Drebin JA, Soper NJ, Klingensmith ME. Portal vein thrombosis after splenectomy. Am J Surg 2002;184:631-5.

47. Carroll BJ, Phillips EH, Semel CJ, Fallas M, Morgenstern L. Laparoscopic splenectomy. Surg Endosc 1992;6:183-5.

48. Delaitre B, Maignien B, Icard P. Laparoscopic splenectomy. Br J Surg 1992;79:1334.

49. Hayashi PH, Mehia C, Joachim Reimers H, Solomon HS, Bacon BR. Splenectomy for thrombocytopenia in patients with hepatitis $\mathrm{C}$ cirrhosis. J Clin Gastroenterol 2006;40:740-4.

50. Shigekawa Y, Uchiyama K, Takifuji K, et al. A laparoscopic splenectomy allows the induction of antiviral therapy for patients with cirrhosis associated with hepatitis $\mathrm{C}$ virus. Am Surg 2011;77:174-9.

51. Watanabe Y, Horiuchi A, Yoshida M, et al. Significance of laparoscopic splenectomy in patients with hypersplenism. World J Surg 2007;31:549-55.

52. Ushitora Y, Tashiro H, Takahashi S, et al. Splenectomy in chronic hepatic disorders: Portal vein thrombosis and improvement of liver function. Dig Surg 2011;28:9-14.

53. Ikeda M, Sekimoto M, Takiguchi S, et al. High incidence of thrombosis of the portal venous system after laparoscopic splenectomy: A prospective study with contrast-enhanced CT scan. Ann Surg 2005;241:208-16.

54. Harris W, Marcaccio M. Incidence of portal vein thrombosis after laparoscopic splenectomy. Can J Surg 2005;48:352-4.

55. Kinjo N, Kawanaka H, Akahoshi T, et al. Risk factors for portal venous thrombosis after splenectomy in patients with cirrhosis and portal hypertension. Br J Surg 2010;97:910-6.

56. Hashizume M, Tomikawa M, Akahoshi T, et al. Laparoscopic splenectomy for portal hypertension. Hepatogastroenterology 2002;49:847-52.

57. Zhu JH, Wang YD, Ye ZY, et al. Laparoscopic versus open splenectomy for hypersplenism secondary to liver cirrhosis. Surg Laparosc Endosc Percutan Tech 2009;19:258-62. 
58. Kercher KW, Carbonell AM, Heniford BT, Matthews BD, Cunningham DM, Reindollar RW. Laparoscopic splenectomy reverses thrombocytopenia in patients with hepatitis $\mathrm{C}$ cirrhosis and portal hypertension. J Gastrointest Surg 2004;8:120-6.

59. Wang Y, Zhan X, Zhu Y, Xie Z, Zhu J, Ye Z. Laparoscopic splenectomy in portal hypertension: A single-surgeon 13-year experience. Surg Endosc 2010;24:1164-9.

60. Patel AG, Parker JE, Wallwork B, et al. Massive splenomegaly is associated with significant morbidity after laparoscopic splenectomy. Ann Surg 2003;238:235-40.

61. Maddison EF. Embolic therapy of hypersplenism. Invest Radiol 1973;8:280-1.

62. Witte CL, Ovitt TW, Van Wyck DB, Witte MH, O'Mara RE, Woolfenden JM. Ischemic therapy in thrombocytopenia from hypersplenism. Arch Surg 1976;111:1115-21.

63. Wholey MH, Chamorro HA, Rao G, Chapman W. Splenic infarction and spontaneous rupture of the spleen after therapeutic embolization. Cardiovasc Radiol 1978;1:249-53.

64. Hayashi H1, Beppu T, Okabe K, et al. Therapeutic factors considered according to the preoperative splenic volume for a prolonged increase in platelet count after partial splenic embolization for liver cirrhosis. J Gastroenterol 2010;45:554-9.

65. Hayashi H, Beppu T, Okabe K, Masuda T, Okabe H, Baba H. Risk factors for complications after partial splenic embolization for liver cirrhosis. Br J Surg 2008;95:744-50.

66. Lee CM, Leung TK, Wang HJ, et al. Evaluation of the effect of partial splenic embolization on platelet values for liver cirrhosis patients with thrombocytopenia. World J Gastroenterol 2007;28:619-22.

67. Zhu K, Meng X, Qian J, et al. Partial splenic embolization for hypersplenism in cirrhosis: A long-term outcome in 62 patients. Dig Liver Dis 2009;41:411-6.

68. Mukaiya M, Hirata K, Yamashiro K, Katsuramaki T, Kimura H, Denno R. Changes in portal hemodynamics and hepatic function after partial splenic embolization (PSE) and percutaneous transhepatic obliteration (PTO). Cancer Chemother Pharmacol 1994:(33 Suppl):S37-S41.

69. Sakai T, Shiraki K, Inoue $\mathrm{H}$ et al. Complications of partial splenic embolization in cirrhotic patients. Dig Dis Sci 2002;47:388-91.

70. N'Kontchou G, Seror O, Bourcier V, et al. Partial splenic embolization in patients with cirrhosis: Efficacy, tolerance and long-term outcome in 32 patients. Eur J Gastroenterol Hepatol 2005;17:179-84

71. Romano M, Giojelli A, Capuano G, Pomponi D, Salvatore M. Partial splenic embolization in patients with idiopathic portal hypertension. Eur J Radiol 2004;49:268-73.

72. Amin MA, el-Gendy MM, Dawoud IE, Shoma A, Negm AM, Amer TA. Partial splenic embolization versus splenectomy for the management of hypersplenism in cirrhotic patients. World J Surg 2009;33:1702-10.

73. Hernandez F, Blanquer A, Linares M, Lopez A, Tarin F, Cervero A. Autoimmune thrombocytopenia associated with hepatitis $\mathrm{C}$ virus infection. Acta Haematol 1998;99:217-20.

74. Pockros PJ, Duchini A, McMillan R, Nyberg LM, McHutchison J, Viernes E. Immune thrombocytopenic purpura in patients with chronic hepatitis $\mathrm{C}$ virus infection. Am J Gastroenterol 2002;97:2040-5.

75. Liu Q, Ma K, He Z, et al. Radiofrequency ablation for hypersplenism in patients with liver cirrhosis: A pilot study. J Gastrointest Surg 2005;9:648-57.

76. Feng K, Ma K, Liu Q, Wu Q, Dong J, Bie P. Randomized clinical trial of splenic radiofrequency ablation versus splenectomy for severe hypersplenism. Br J Surg 2011;98:354-61.
77. Liu Q, Ma K, Song Y, Zhou N, He Z. Two-year follow-up of splenic radiofrequency ablation in patients with cirrhotic hypersplenism: Does increased hepatic arterial flow induce liver regeneration? Surgery 2008;143:509-18.

78. Mutchnick MG, Lerner E, Conn HO. Portal-systemic encephalopathy and portacaval anastomosis: A prospective, controlled investigation. Gastroenterology 1974;66:1005-19.

79. Vang J, Simert G, Hansson JA, Thylen U, Bengmark TS. Results of a modified distal spleno-renal shunt for portal hypertension. Ann Surg 1977;185:224-8.

80. Alvarez OA, Lopera GA, Patel V, Encarnacion CE, Palmaz JC, Lee M. Improvement of thrombocytopenia due to hypersplenism after transjugular intrahepatic portosystemic shunt placement in cirrhotic patients. Am J Gastroenterol 1996;91:134.

81. Lawrence SP, Lezotte DC, Durham JD, et al. Course of thrombocytopenia of chronic liver disease after transjugular intrahepatic portosystemic shunts (TIPS). A retrospective analysis. Dig Dis Sci 1995;40:1575.

82. Pursnani KG, Sillin LF, Kaplan DS. Effect of transjugular intrahepatic portosystemic shunt on secondary hypersplenism. Am J Surg 1997;173:169.

83. Sanyal AJ, Freedman AM, Purdum PP, et al. The hematologic consequences of transjugular intrahepatic portosystemic shunts. Hepatology 1996;23:32.

84. Jabbour N, Zajko A, Orons P, Irish W, Fung JJ, Selby RR. Does transjugular intrahepatic portosystemic shunt (TIPS) resolve thrombocytopenia associated with cirrhosis? Dig Dis Sci 1998;43:2459-62.

85. Boyer TD, Haskal Z. AASLD Practice Guidelines: The role of transjugular intrahepatic portosystemic shunt in the management of portal hypertension. Hepatology 2010;51:1-16.

86. Rajan S, Liebman HA. Treatment of hepatitis C related thrombocytopenia with interferon alpha. Am J Hematol 2001;68:202-9.

87. Iga D, Tomimatsu M, Endo H, Ohkawa S, Yamada O. Improvement of thrombocytopenia with disappearance of $\mathrm{HCV}$ RNA in patients treated by interferon-alpha therapy: Possible etiology of HCV-associated immune thrombocytopenia. Eur J Haematol 2005; 75:417-23

88. Lin A, Thadareddy A, Goldstein MJ, Lake-Bakaar G. Immune suppression leading to hepatitis $\mathrm{C}$ virus re-emergence after sustained virological response. J Med Virol 2008;80:1720-2.

89. Lladó L, Fabregat J, Castellote J, et al; THOSIN Study Group. Impact of immunosuppression without steroids on rejection and hepatitis $\mathrm{C}$ virus evolution after liver transplantation: Results of a prospective randomized study. Liver Transpl 2008;14:1752-60.

90. Lake JR. The role of immunosuppression in recurrence of hepatitis C. Liver Transpl 2003;9:S63-6.

91. Li J, Yang C, Xia Y, et al. Thrombocytopenia caused by the development of antibodies to thrombopoietin. Blood 2001;98:3241-8.

92. McHutchison JG, Dusheiko G, Shiffman ML, et al; TPL102357 Study Group. Eltrombopag for thrombocytopenia in patients with cirrhosis associated with hepatitis C. N Engl J Med 2007;29:2227-36.

93. The ELEVATE study. <www.clinicaltrials.gov> TPL104054. Clincal Trial.gov NCT00678587 (Accesed March 1, 2013).

94. Afdhal NH, Dusheiko GM, Theodore D, et al. Eltrombopag increases platelet numbers in thrombocytopenic patients with $\mathrm{HCV}$ infection andcirrhosis, allowing for effective antiviral therapy. Gastroenterology 2014;146:442-52.

95. Dultz G, Kronenberger B, Azizi A, et al. Portal vein thrombosis as complication of romiplostim treatment in a cirrhotic patient with hepatitis C-associated immune thrombocytopenic purpura. J Hepatol 2011;55:229-32. 


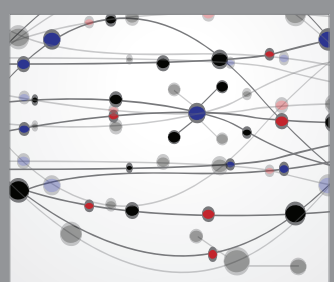

The Scientific World Journal
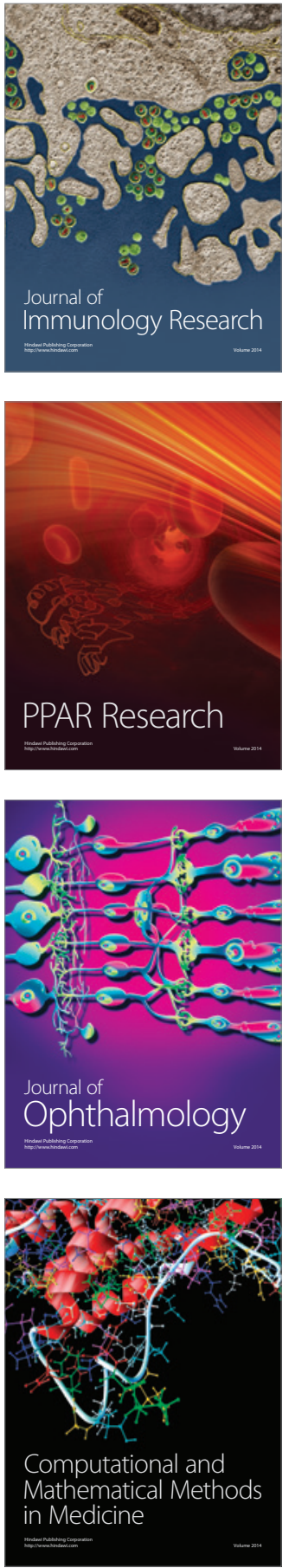

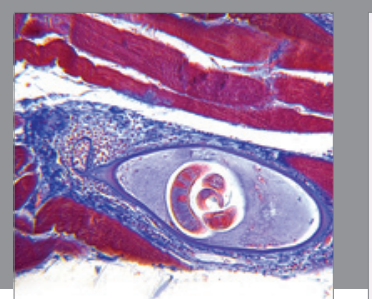

Gastroenterology Research and Practice

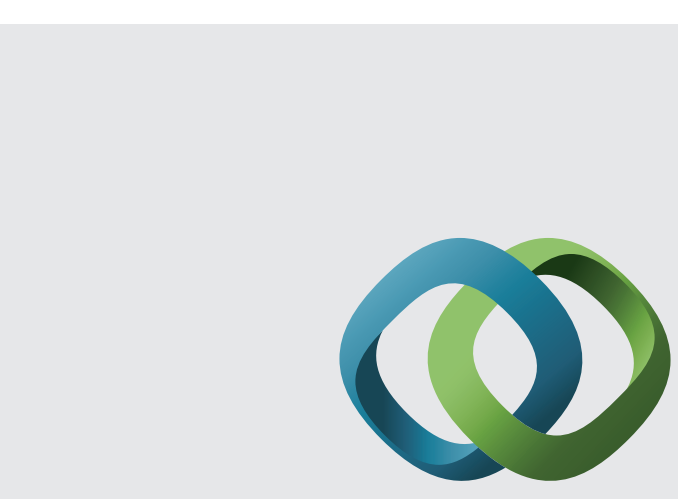

\section{Hindawi}

Submit your manuscripts at

http://www.hindawi.com
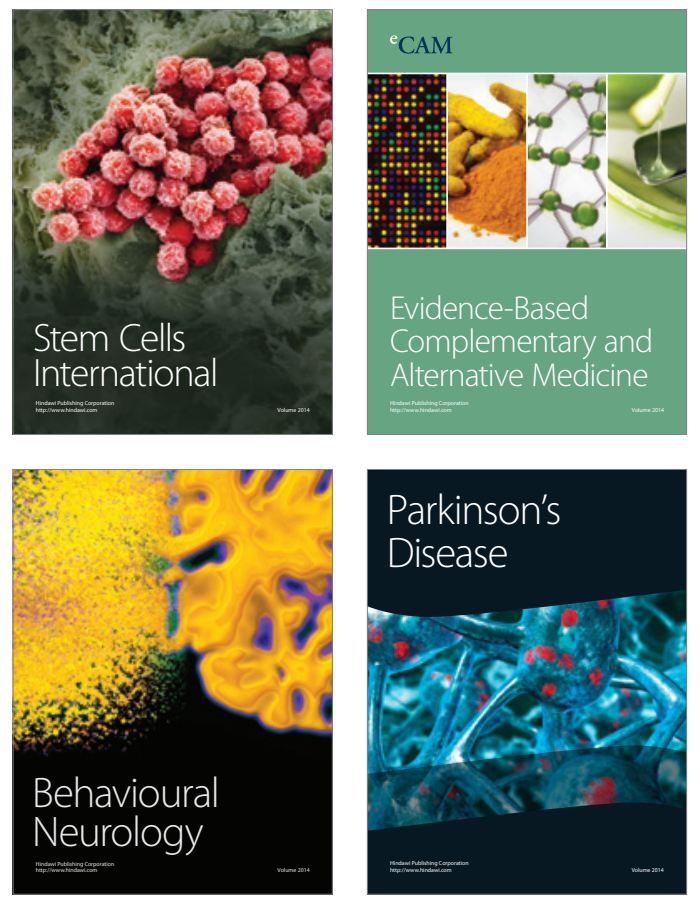
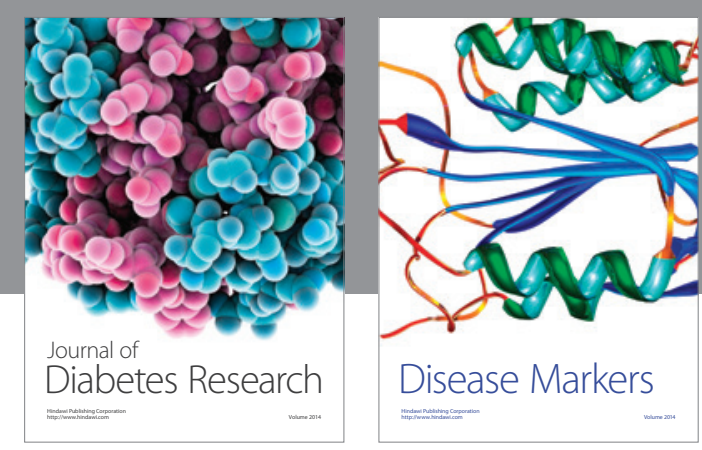

Disease Markers
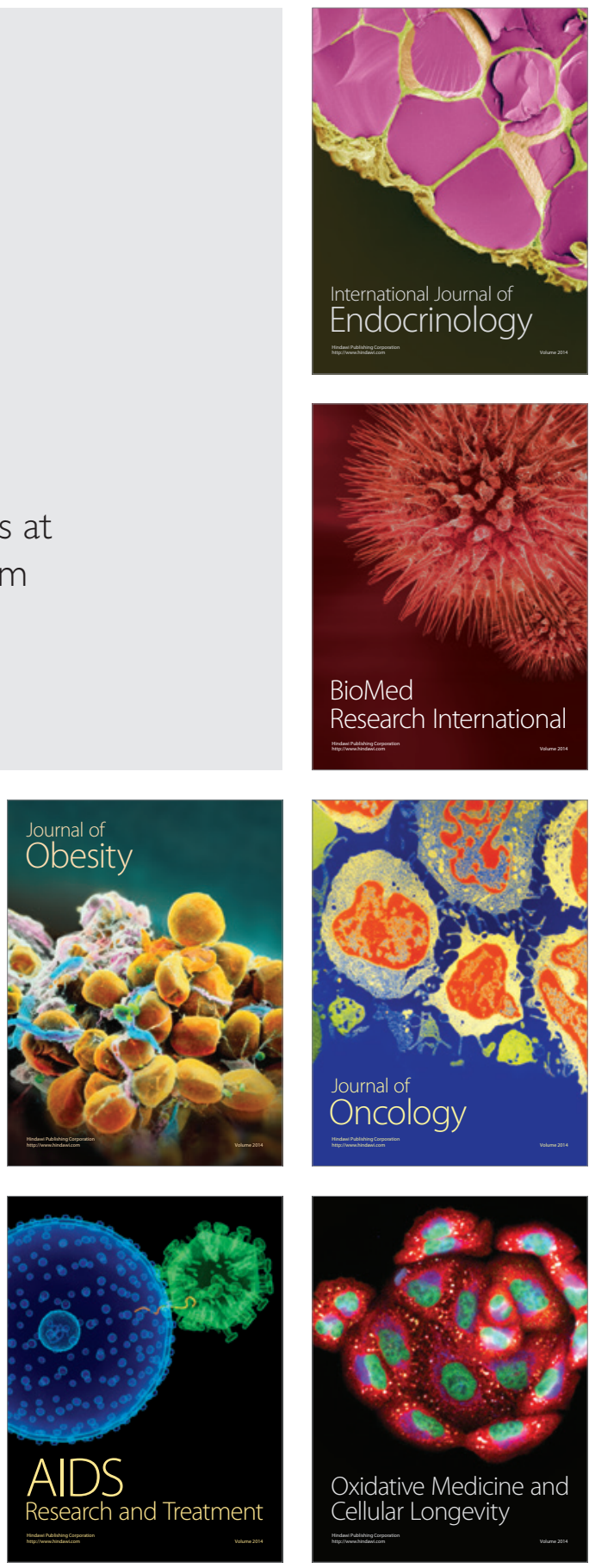